\title{
Thoughts on China's Rural Ecological Security Construction from the Perspective of Overall National Security Concept
}

\author{
Jianlan Yang, Miao Guo \\ School of Economics Management and Law, University of South China, Hengyang 421001, Hunan, China
}

\begin{abstract}
As a national security thought in the new era, the overall national security concept contains rich security governance theory and practical experience, which provides a scientific guide and program for the development of various security work in China. Rural ecological security, as an organic component of overall national security, interpenetrates and interacts with other areas of security, and counteracts the realization of overall national security. Based on the overall national security concept, the rural ecological security construction should adhere to the bottom line thinking, people-oriented, innovation-oriented and rule of law, and conceive an optimized path in the aspects of pre-prevention, public demand, talent integration, collaborative governance, technical means and legal system construction, which is of great significance to national development and people's lives.
\end{abstract}

Keywords: Overall national security concept, Rural ecological security, Ecological security construction.

\section{Rural Ecological Security is an Organic Part of Overall National Security}

The general concept of national security is a basic strategy put forward by the CPC Central Committee with President Xi Jinping as the core, based on China's current security situation, aiming at coping with various security challenges and maintaining overall national security. Rural ecological security, as one of the constituent elements of the overall national security, has a partial and integral relationship with the overall national security, which is interdependent and mutually influential. Overall national security is an organic whole composed of different security elements in many fields, which is the premise and foundation of building rural ecological security. It is in a leading position between the two and provides a good atmosphere and realistic support for the construction of rural ecological security. Rural ecological security is an organic component of the overall national security, which is in a subordinate position between the two, permeates and interweaves with other areas of security, and counteracts the realization of the overall national security.

\subsection{Rural Ecological Security and People's Safety}

Ecology is the foundation of people's survival and life, but in recent years, air pollution, water pollution, soil erosion, forest degradation and other issues have affected people's daily life. In rural areas, ecological problems such as burning platycodon grandiflorum and surrounding villages with garbage have brought inconvenience and troubles to farmers' production and life, and even threatened their survival. It can be said that there is a direct connection between rural ecological security and people's security.

\subsection{Rural Ecological Security and Economic Security}

Economic security means that individuals have certain income or resources to ensure a stable life, and the national economy has the ability to resist external risks and achieve long-term development in a healthy state. As a large agricultural country in China, a good rural ecology provides a rich material foundation for China's production activities, agricultural development and economic operation, and is a powerful support for sustainable economic development. Economic security cannot be separated from rural ecological security.

\subsection{Rural Ecological Security and Resource Security}

As an essential natural substance, resources participate in the whole process of human survival and development. Rural ecology contains a large number of factors of production resources that promote the development of rural industries, which is an important carrier for continuously obtaining natural resources in the development process of our country. At the same time, good rural ecological security is conducive to building a healthy resource system, improving the ability of resource guarantee, ensuring the safety of water resources and land resources, etc., which is an important factor affecting resource security.

\subsection{Rural Ecological Security and Social Security}

Rural ecological security is closely related to social security. In the predicament of limited development, farmers are vulnerable to transferring negative externalities in production, survival and life to the ecological field in order to protect their own interests, which leads to further deterioration of rural ecological security, directly undermines the harmonious development of rural areas, threatens and challenges the safety of farmers' production and life, and may even trigger vicious mass incidents, thus undermining social security.

In a word, rural ecological security is closely related to overall national security, interlocking with other security, and is the key factor to achieve overall national security. Therefore, from the perspective of the overall national security concept, it is of great significance to analyze the rural ecological 
security construction into the overall national security, take the overall national security concept as the basic compliance, and think deeply about the optimization path of rural ecological security construction in China.

\section{The Construction of Rural Ecological Security is Based on the Overall National Outlook}

The overall national security concept contains bottom line thinking, people-oriented thinking, talent thinking, innovative thinking and rule of law thinking, which is a holistic and systematic overall national security concept, providing scientific guidance for China's rural ecological security construction, which should be basically followed by the overall national security concept.

\subsection{Rural Ecological Security Construction Should Adhere to the Bottom Line Thinking}

Since the founding of the People's Republic of China, the reason why China has made great progress and great achievements in safety maintenance and governance, and has been able to constantly resist risks, cope with challenges, resolve contradictions and overcome resistance is that bottom-line thinking and sense of hardship have played a constant vigilance role. The bottom line thinking runs through the overall national security concept. At present, it is difficult for China's rural ecological security construction to meet the needs of risk prevention, precisely because of the lack of bottom-line thinking and inadequate prevention work in advance. General Secretary Xi Jinping pointed out that we should always keep a high degree of vigilance, prevent all kinds of ecological environment risks from accumulating and spreading, and be prepared to deal with any form of ecological environment risks[1]. Both the analysis of the rural ecological security situation with complex influencing factors and the practical guidance of rural ecological security construction advocate and advocate keeping high vigilance at all times, not only to solve the outstanding rural ecological security problems at present, but also to guard against various potential ecological crises and risks in the future, so as to combine effective prevention with active control and take the initiative in the process of rural ecological security construction.

\subsection{Rural Ecological Security Construction Should Adhere to People-Oriented}

For the first time, the overall concept of national security has raised people's safety to the height of national security, taking people's safety as its purpose and putting people's safety at the top of the national security system, which is an important embodiment of putting people first. However, at present, the farmers' ecological requirements in rural areas of China has not been effectively met, and the support of infrastructure and public resources is insufficient. Therefore, General Secretary $\mathrm{Xi}$ Jinping pointed out that the needs of the people are characterized by diversity, multi-level and multi-faceted, and it is necessary to firmly grasp the people's yearning for a better life and put forward new ideas, new strategies and new measures[2]. China's rural ecological security construction should constantly respond to people's demands for ecological security in rural areas, and provide a solid guarantee for the realization of rural ecological security and the improvement of farmers' happiness in life. At the same time, the overall concept of national security advocates that talents from all sides join in the realization and guarantee of national security, which is an important manifestation of putting talents first. In view of the shortage of talents and the low degree of specialization in rural ecological security construction, General Secretary Xi Jinping pointed out that it is necessary to establish a strong awareness of talents, to seek talents for talents, to find talents as valuable as possible, to recommend talents to be eclectic, and to use talents to their best[3]. The construction of rural ecological security can not be separated from the support of all kinds of talents, and the continuous coordination and transportation of human resources is the urgent need and basic project to realize rural ecological security in China.

\subsection{Rural Ecological Security Construction Should Adhere to Innovation Orientation}

According to the new situation facing national security, the overall concept of national security is an innovation and transcendence of the previous concept of national security governance, which updates the concept and content of national security governance, innovates the means of national security governance and construction, and provides new guidance for China's international and domestic security construction. General Secretary Xi Jinping pointed out that innovation is the soul of a nation's progress, the inexhaustible motive force for a country's development and prosperity, and the deepest national endowment of the Chinese nation[4]. It is necessary to create a social governance pattern of co-construction, governance and sharing[5]. At present, in the process of rural ecological security construction in China, some construction subjects are backward in concept and low in participation consciousness, and the modernization platform and technology are not perfect and the utilization rate is low. Therefore, rural ecological security should also constantly update the governance concept, structure and means, so as to further correct the ideological misunderstanding in the process of rural ecological security construction in China in the theoretical dimension, and guide the development of practical activities with correct concepts. In the practical dimension, we should further optimize the main structure of rural ecological security construction, innovate construction means and continuously improve the construction level.

\subsection{Rural Ecological Security Construction Should be Guided by the Rule of Law}

China's governance system and capacity are based on the rule of law. The overall national security concept always advocates the rule of law, attaches great importance to the construction and optimization of China's security laws, standardizes and maintains the basic laws in various security fields in China, and promotes China's national security rule of 
law work to a new stage. However, due to the scattered, general and vague related policies, laws and mechanisms, the construction of rural ecological security in China is not guaranteed by the rule of law. Therefore, General Secretary Xi Jinping pointed out that only the strictest system and the strictest rule of law can provide a reliable guarantee for the construction of ecological civilization[6]. Rural ecological security construction should build and constantly improve a scientific and complete ecological security legal system, which is based on the actual situation of rural ecological security in China, conforms to the requirements and trends of the times, promotes all the work related to the construction and maintenance of rural ecological security to enter the track of legalization, continuously improves the legalization level of rural ecological security construction, and provides comprehensive legal support and legal guarantee for the construction and realization of rural ecological security, so as to ensure the smooth development of rural ecological security construction.

\section{The New Era of China's Rural Ecological Security Construction Path Optimization}

General Secretary Xi Jinping pointed out that Jinshan Yinshan is important for people's survival, but green mountains and green hills are an important part of people's happy life, which cannot be replaced by money[7]. According to the overall national security concept, continuously optimizing the construction path not only responds to the new demands and demands of the Party and the people for rural ecological security construction, but also conforms to the new trend of rural ecological security issues under the theme of the times, and also responds to the new issues arising in the long-term strategy of rural ecological security construction.

3.1 Take Precautions in Advance as the First Step, and Realize the Continuous Advancement of the Gateway

Any work can't ignore the great role of prevention in advance, and complete risk prevention work is an important foundation for promoting rural ecological security construction. The overall concept of national security is a holistic and systematic concept of national security, which implements the bottom line thinking and sense of hardship, and pays attention to the whole stage of safety construction and all types of risks. General Secretary $\mathrm{Xi}$ Jinping emphasized that any accumulation of risks would threaten regional and even global security. In view of the risk prevention work in rural ecological security construction, we should pay attention to the following two aspects. On the one hand, establish the awareness of ecological security and improve the awareness of ecological risks. The establishment and strengthening of farmers' awareness of ecological security is a prerequisite for promoting rural ecological security prevention. We should strengthen the investment in rural safety education and promote the development of its safety education. Besides setting up special funds and offering related courses, we should broaden the channels of safety education, strengthen the popularization of ecological security knowledge by using mobile phone short messages, radio and other means, and provide reliable external guarantee. On the other hand, improve the early warning mechanism of rural ecological security. Collect and integrate rural ecological security information, build an early warning network that can comprehensively cover rural areas, strengthen rural ecological security risk monitoring, and design feasible and effective solutions for various potential risks to achieve accurate and efficient prevention; At the same time, it analyzes the ecological security risks that occurred in the past, sums up the areas and types of risks that should be focused on, and carries out risk avoidance and prevention in the whole process so as to move forward.

\subsection{Guided by Public Demand, Optimize Hard and Soft Support}

The overall concept of national security is based on people's safety, insisting on people's supremacy, and its outstanding feature is people's nature. In view of people's diverse demands for ecological construction, General Secretary Xi Jinping has repeatedly stressed the need to pay attention to people's livelihood. Therefore, in the construction of rural ecological security, we should first improve the construction of hardware facilities and enhance rural public services. On the basis of thoroughly analyzing the existing problems of ecological environment security in rural areas, some ecological problems are solved by improving infrastructure, such as continuously promoting the construction of sewage treatment plants and the "toilet revolution" activities, thus improving the rural living environment and strengthening the hard foundation security. At the same time, we should formulate public policies that meet people's needs, promote the balanced and optimized allocation of various public resources, strengthen the supply of public services in rural areas, continuously improve the supply capacity and level of public services, and optimize soft support. Secondly, build a demand expression mechanism to accurately meet the needs of villagers. In the final analysis, the lack of demand expression mechanism is the reason why the ecological security needs of rural residents have not been responded. Therefore, we should create a variety of demand expression channels, communicate with villagers by telephone and WeChat while visiting and receiving visiting villagers regularly, and adopt online and offline methods to tap the individual needs of villagers, and plan the focus of rural ecological security construction on the basis of fully understanding the relevant wishes and demands of villagers, so as to meet the individual needs of villagers and ensure the balanced development of rural ecological security construction.

\subsection{Follow the Talent Thought and Continuously Integrate the Talent Resources}

The comprehensiveness and openness of the overall national security concept means that there are various problems in the process of rural ecological security construction, and it is considered that talents are the key to solve the problems. However, according to the seventh census bulletin, compared with the previous data, the rural population decreased by 
$164,361,984$. In view of the scarcity of rural construction talents, General Secretary Xi Jinping emphasized guiding all kinds of talents to flow to the countryside. Therefore, we can make overall plans for building talents from two aspects of talent attraction and talent cultivation. In terms of external material conditions, employees' salaries can be appropriately increased, and other welfare inputs can be increased. From the perspective of internal spiritual needs, we can strengthen the spiritual encouragement to the ecological security construction personnel through the relevant talent evaluation mechanism. At the same time, strengthen the national policy support for talent introduction in rural areas, such as continuously promoting the project of encouraging college graduates to return home, and constantly improve the activity of talent inflow and the return rate of outstanding talents, so as to input more young talents for the construction of rural ecological security and further reduce the aging phenomenon of the talent team. In addition, various training resources are integrated to enrich the content and form of training. Professional knowledge training and professional skills teaching are provided to the personnel involved in ecological security construction, so as to improve their professional quality and guide their practice with professional theories, so that they can quickly understand and master the work requirements, correctly and scientifically respond to the problems in the process of rural ecological security construction, and improve the professionalization of the construction team.

\subsection{Change the Concept, Reshape the Structure, and Realize Multi-Party Cooperation and Governance}

The overall national security concept requires that rural ecological security construction should be coordinated by all parties and promoted systematically. General Secretary $\mathrm{Xi}$ Jinping has repeatedly stressed that it is necessary to improve social governance methods and give full play to the roles of all parties. It is the forerunner of action. To achieve multi-party cooperation and governance in rural ecological security construction, we must change the construction concept and reshape the main structure. On the one hand, it is necessary to update the traditional construction concept and improve the participation consciousness of stakeholders in ecological security construction. In the process of construction, we should awaken villagers' awareness of participation and improve villagers' degree of participation. Cultivate the spontaneity of social organizations and enterprises in rural ecological security construction. At the same time, it is necessary to break the inherent development concept of some officials. It is necessary for them to realize that ecological security construction is not the supremacy of economy, and GDP alone will only bring adverse effects to rural ecological security construction, resulting in abnormal development of ecological security construction. On the other hand, it is necessary to enrich the construction subjects, strengthen the interaction and integration of the subjects' behaviors, and realize the cooperative governance of multiple subjects. Under the leadership of grass-roots party committees, we should formulate ecological security construction plans according to the actual situation, broaden the channels for villagers to participate in ecological security construction and encourage villagers to participate in ecological security construction; Break the current situation of taking interests as the link, attract social organizations and enterprises to join on the basis of trust, expand the rural ecological security construction team and enrich the main structure of construction. At the same time, the mutual supervision among the government, villagers and enterprises should be strengthened to achieve a win-win situation of ecological and economic benefits in rural ecological security construction.

\subsection{Means and Technology Innovation, Improve the Effectiveness of Construction}

The overall concept of national security is the product of the times, and its epochal and innovative nature puts forward new requirements for the means and technology of building rural ecological security. In the process of rural ecological security construction, the problems with the characteristics of the times are increasing, and the demand for modern data technology is increasing. General Secretary $\mathrm{Xi}$ Jinping advocates adopting intelligent construction means and modernizing construction technology to continuously improve the construction level. In terms of construction means, the government can establish and optimize the network service platform, integrate the data and information resources of rural ecological security construction, and form an open and shared database to reduce the occurrence of resource fragmentation. Learn from the urban ecological construction mode, take the Internet as the connection, and rely on the new media platform to strengthen the effective communication among grass-roots organizations, villagers and enterprises, so as to realize the organic combination of online and offline construction means informationization. Technically, rural areas in China should abandon some traditional methods that are no longer adaptable, such as random landfill, and accelerate the introduction and application of modern ecological safety technology in the process of treating sewage and domestic garbage, so as to reduce secondary pollution in the process of treatment. At the same time, we should popularize the knowledge of modern science and technology to farmers and guide them to use materials beneficial to ecological security, such as organic fertilizer. In addition, we should speed up the independent innovation of green technology, increase local investment in modern technology research, and give full play to the role of modern ecological technology in rural ecological security construction.

\subsection{Take the Construction of the Rule of Law as the Guarantee and Fill in the Shortcomings of Ecological Rule of Law}

The rule of law features of the overall national security concept provide reference for rural ecological security construction, which requires that the construction of rural ecological security should be reliably guaranteed by relevant laws and regulations. Facing the problems of lax rule of law in rural ecological security construction, General Secretary Xi Jinping emphasized that environmental protection must rely 
on the rule of law. The premise of legal protection is that there are laws to follow. Therefore, we should first optimize the legislative work of rural ecological security construction in China. Modify the unreasonable parts in the relevant legal system in time, make up for and repair the existing loopholes and blank areas, and make the framework and principle content, so as to improve its feasibility. Second, improve the supervision and accountability mechanism. Clear the division of responsibilities of supervision departments, strengthen the information flow and behavior interaction among departments, actively guide public participation on the basis of exerting their joint efforts in supervision, expand supervision channels and give full play to their roles. At the same time, it is necessary to clarify the responsibilities among the subjects in the process of ecological security construction according to law, comprehensively evaluate the behavior and activities of each subject, investigate the responsibility of the subjects who have caused damage to ecological security, and judge and clarify that the responsible subjects are the basis for paying compensation. Finally, improve the compensation mechanism of rural ecological security. Perfect ecological security compensation mechanism can promote ecological security protection. Clearly define the principles of compensation basis, price and method, and innovate ecological security compensation methods, such as transfer payment and horizontal compensation, so as to provide effective guarantee for rural ecological restoration and ensure the smooth development of rural ecological compensation.

\section{References}

[1] Wu Xiqi. Always keep in mind when you are prepared for danger.[EB/OL]. people.cn: http://theory.people.com.cn/n1/2018/0108/c409497-297 52123.html.

[2] Ran Hao. Strive to realize the people's yearning for a better life.[EB/OL]. people.cn: http://theory.people.com.cn/n1/2017/0814/c40531-2946 7931.html.

[3] Shen Ronghua. The core of Xi Jinping's talent view: gathering talents from all over the world and using them.[EB/OL].

people.cn: http://theory.people.com.cn/n1/2017/0629/c40531-2937 0538.html.

[4] Zhao Yujie. Xi Jinping's Scientific Thinking Mode of Governing the Country.[EB/OL]. people.cn: http://theory.people.com.cn/n1/2017/0120/c40531-2903 8623.html.

[5] Research Institute of Party History and Literature, Central Committee of the Communist Party of China. Excerpts from Xi Jinping's exposition on the overall national security concept[M]. Beijing: Central Literature Publishing House, 2018: 141.

[6] Research Institute of Party History and Literature, Central Committee of the Communist Party of China. Excerpts from Xi Jinping's exposition on the overall national security concept[M]. Beijing: Central Literature Publishing House, 2018: 168.

[7] Research Institute of Party History and Literature, Central Committee of the Communist Party of China. Excerpts from Xi Jinping's exposition on the overall national security concept[M]. Beijing: Central Literature Publishing House, 2018: 166.

\section{Author Profile}

Jianlan Yang (1969-), male, Ph.D. Researcher, School of Economics Management and Law, University of South China, Party secretary of Chuanshan College.

Miao Guo (1997-), female, graduate student in School of Economics Management and Law, University of South China, and has been studying for a Master's degree since 2019. 